\title{
Evaluation of Ultimate Strength and Fundamental Frequency of Fiber/Epoxy and Fiber/Al6061 Composite Plate
}

\author{
Manoj Verma $^{1, *(\mathbb{D})}$, Ajay Kumar Verma ${ }^{2} \mathbb{D}$, Vikky Kumhar ${ }^{2}(\mathbb{D}$ \\ 1 Department of Energy \& Environmental Engineering, UTD-Chhattisgarh Swami Vivekananda Technical University, \\ Durg, Chhattisgarh, 491107 India \\ 2 Department of Mechanical Engineering, FET-SSGI, Shri Shankaracharya Technical Campus, Bhilai, 491107 Chhattisgarh, \\ India \\ * Correspondence: manojverma.csvtu@gmail.com (M.V.);
}

Scopus Author ID 36877094800

Received: 3.06.2021; Revised: 15.07.2021; Accepted: 19.07.2021; Published: 8.08.2021

\begin{abstract}
Polymers and metal composites have emerged as a significant class of materials for cuttingedge engineering applications in the current material research and development environment because of their low cost, ease of design and manufacturing, and excellent and enhanced mechanical performances. The motto behind the present work is to develop a class of such materials and to study the mechanical properties of epoxy-based Glass (G/E), Graphite (Gr/E), Aramid (A/E), Carbon HM Types (C/E), and Multi-Walled Carbon Nanotube Composites (MWCNT/E) and aluminum-based MWCNT composites. An analytical solution and finite element analysis are used to evaluate and obtain the optimum mechanical properties of the lamina of the composites, such as ultimate longitudinal tensile strength, transverse tensile strength, shear strength, and the fundamental frequency of the composite plate analysis. All-side fixed boundary conditions have been used in the present study. In addition to the above, a detailed demonstrative analysis based on the after-effects of the modulus ratio and the volume fraction of the fiber on the ultimate tensile strength has also been made. In addition, the CNT AMC plate has been examined, with the findings being compared to the composite plate of Epoxy Metal Matrices (EMCs).
\end{abstract}

Keywords: composite material; CNT; finite element analysis; frequency; metal matrix; polymer matrix; ultimate strength.

(C) 2021 by the authors. This article is an open-access article distributed under the terms and conditions of the Creative Commons Attribution (CC BY) license (https://creativecommons.org/licenses/by/4.0/).

\section{Introduction}

Inside the final structure, composite materials are made up of two or more constituent materials with significantly different physical and chemical characteristics that remain distinct and distinct at both the macroscopic and microscopic dimensions. These are materials that have reinforcement, which is a strong load-bearing material, embedded in a matrix, which is a weaker material. Reinforcement adds strength and stiffness to a structure, allowing it to support more weight. The reinforcement's location and orientation are maintained by the matrix or binder (organic or inorganic). The reinforcement might be particles, platelets, or fibers, and it's commonly used to increase the matrix material's mechanical properties, including stiffness, strength, and toughness.

The most efficient load transmission is achieved with long fibers that are aligned in the loading direction. In addition, wear resistance, fatigue life, stiffness, thermal insulation, 
corrosion resistance, strength, acoustic insulation, temperature-dependent behavior, and so on are some of the features enhanced by making composite material [1-3]. As illustrated in Figure 1, composite materials are composed of two or more constituent materials with vastly diverse physical and chemical characteristics that remain distinct and distinct at the macroscopic and microscopic scales inside the completed structure [4-6].

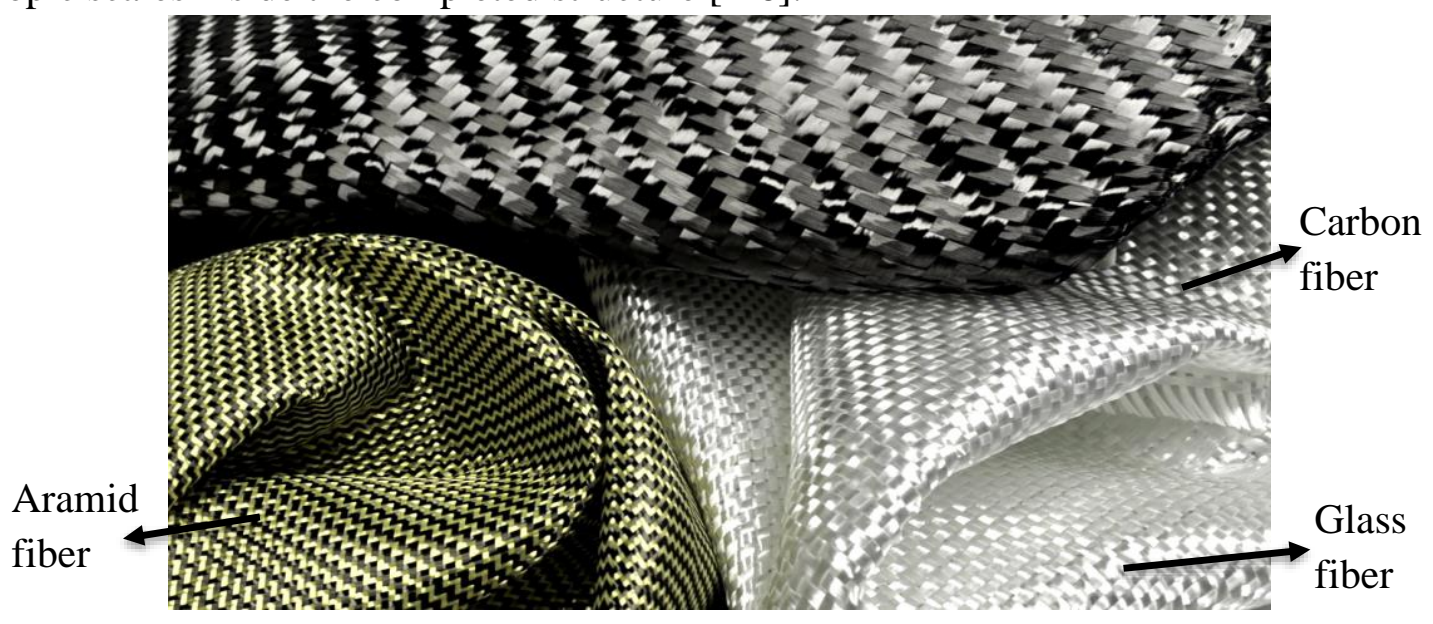

Figure 1. Composite material

Composite materials may be divided into three classes based on matrix materials, as indicated in Figure 2.



Figure 2. Classification of composite [6].

\section{Literature review}

Carbon Nanotubes are still in the research stage and have no commercial applications. However, these composites might be utilized to create brake shoes, cylinder liners, and aircraft landing gears in the automotive and aerospace industries because of their low density, high strength, and superior wear resistance [5]. Furthermore, its high elastic modulus can create lowweight bicycles, tennis balls, and badminton rackets in the sports industry. Thus, by overcoming processing obstacles and gaining improved mechanical characteristics, CNT composites can be used in real-world applications. As a result, the current work will thoroughly 
examine the research conducted with different fibers such as glass, graphite, aramid, and CNTs as reinforcement in epoxy and aluminum metal matrix composites.

Many researchers have employed different composite materials to analyze and get the best mechanical characteristics of various challenges based on prior and current research efforts [7-19]. Using an $\mathrm{O}(\mathrm{N})$ TBMD simulation, the authors investigated how temperature impacts structural stability and mechanical qualities and how Al's low density makes it ideal for the automotive and aerospace sectors. Some researchers proposed a different method in which a non-consumable rotating tool was inserted into the work-piece, few presented the composites of aluminum reinforced by CNT produced with CNT-Al agglomerates and aluminum powders, and some investigators studied the array of short fibers in a preform that could be used to disperse the CNTs in the matrix. When the CNTs needed to be dispersed homogeneously in the Al-based matrix, the inventors achieved an optimal level of characteristic mechanical performance. They also investigated the effect of milling time on the structural morphology and consistency of thermal stability of multi-walled carbon nanotubes (MWCNTs) reinforced EN AW6082 Al alloy powders. The authors also applied mechanical alloying (MA) to disperse $\mathrm{CNT}$ in the aluminum matrix. Discoverers studied the composite of Epoxy/Glass material comprising two different micro-fillers developed by the vacuum bagging process. Investigators carried out their research work to study and analyze the behavior concerned with hybrid composites' electrical properties, which are conductive in nature and made with woven ingredients of glass and graphite, nanopowder of graphite along-with phenolic resin, which is applied as collector plates in the electrostatic precipitators. Some studies on matrix composite with $\mathrm{CNTs} / \mathrm{Al}_{2} \mathrm{O}_{3}, \mathrm{CNT}$ reinforced $\mathrm{Al}$ alloy composites by ball milling, quantification in natural frequency of composite plates, the effect of carbon nanotube dispersion on hybrid composites, vibration analysis of polyethylene/CNT plates, vibration analysis of laminated graphene-reinforced composite beams and behavior of cotton fabric composites are examined by the authors. The impacts of geometrical data on mechanical characteristics of composite plates are explored based on a summary report (Table 1) of a certain literature review on composite plates and prior research [20-30].

Table 1. Summary report of literature survey on composite plates.

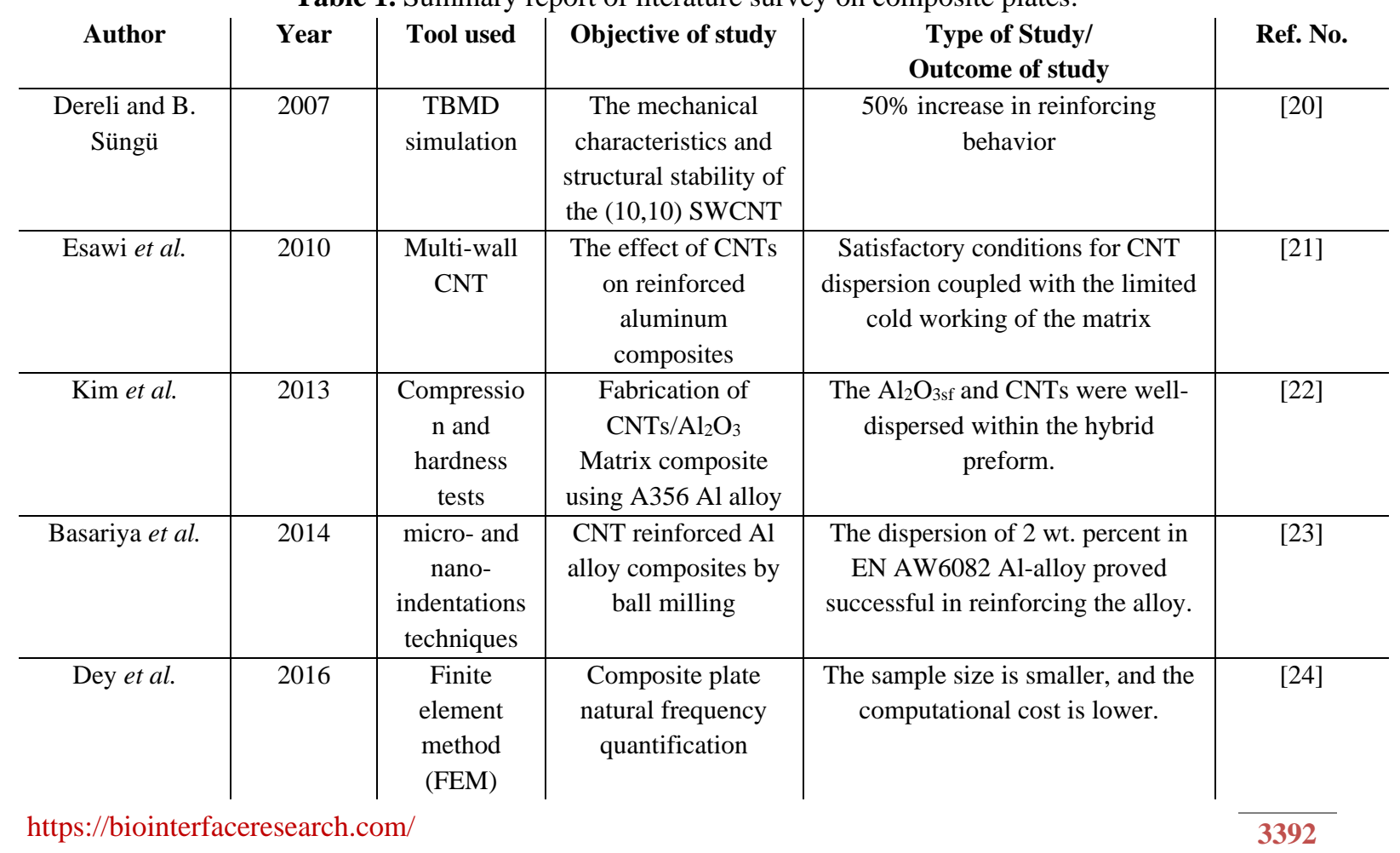




\begin{tabular}{|c|c|c|c|c|c|}
\hline Author & Year & Tool used & Objective of study & $\begin{array}{c}\text { Type of Study/ } \\
\text { Outcome of study }\end{array}$ & Ref. No. \\
\hline Farrash et al. & 2017 & FEM & $\begin{array}{c}\text { Dispersion of carbon } \\
\text { nanotubes in hybrid } \\
\text { composites }\end{array}$ & $\begin{array}{l}\text { The fundamental frequency has } \\
\text { been reduced by } 13.9 \% \text {, and the } \\
\text { damping ratio has been increased } \\
(31.5 \%)\end{array}$ & [25] \\
\hline Reddy et al. & 2018 & $\begin{array}{l}\text { Finite } \\
\text { element } \\
\text { approach }\end{array}$ & $\begin{array}{l}\text { to look at the } \\
\text { behavior of } \\
\text { graphene } \\
\text { nanoplatelets in free } \\
\text { vibration (GPLs) }\end{array}$ & $\begin{array}{c}\text { The effect of GPL fraction, shape, } \\
\text { and size on natural frequencies, as } \\
\text { well as the } \% \text { increase in natural } \\
\text { frequencies }\end{array}$ & [26] \\
\hline Wang et al. & 2018 & ANSYS & $\begin{array}{l}\text { GPL-reinforced } \\
\text { graded } \\
\text { nanocomposite } \\
\text { doubly-curved } \\
\text { shallow shells }\end{array}$ & $\begin{array}{l}\text { The Navier approach is used to get } \\
\text { free vibration frequencies and } \\
\text { bending deflections }\end{array}$ & [27] \\
\hline Safaei et al. & 2019 & $\begin{array}{l}\text { Finite } \\
\text { Element } \\
\text { Method } \\
(\text { FEM })\end{array}$ & $\begin{array}{l}\text { Polyethylene and } \\
\text { CNTs were } \\
\text { subjected to } \\
\text { vibration analysis. }\end{array}$ & $\begin{array}{l}\text { Short }(10,10) \text { and long }(10,10) \\
\text { SWCNTs composites reinforced } \\
\text { composite plates were simulated. }\end{array}$ & [28] \\
\hline Wang et al. & 2019 & $\begin{array}{l}\text { Multi-term } \\
\text { Kantorovich } \\
\text {-Galerkin } \\
\text { method }\end{array}$ & $\begin{array}{l}\text { Analysis of } \\
\text { laminated graphene- } \\
\text { reinforced composite } \\
\text { beams for vibration }\end{array}$ & $\begin{array}{l}\text { The impact of graphene } \\
\text { distribution patterns, boundary } \\
\text { conditions, length-to-thickness } \\
\text { ratios, layer fraction increments, } \\
\text { and layer count is investigated. }\end{array}$ & [29] \\
\hline Ayan et al. & 2020 & $\begin{array}{l}\text { Scanning } \\
\text { electron } \\
\text { microscopy } \\
\text { (SEM) }\end{array}$ & $\begin{array}{l}\text { Behavior of cotton } \\
\text { fabric composites }\end{array}$ & $\begin{array}{c}\text { Cotton can be evaluated as a radar- } \\
\text { absorbing material (RAM) }\end{array}$ & {$[30]$} \\
\hline
\end{tabular}

In the present work, the mechanical properties of EMC's based G/E, Gr/E, A/E, C/E and MWCNT/E composite plate and AMC's CNT composite plate have been evaluated compared with each other, and the same is considered and taken for further investigations. MATLAB has been used for an analytical solution to evaluate the ultimate strength of composite plates, and finite element analysis is used to evaluate the fundamental natural frequency of composite plates.

\section{Methodology}

A systematic approach to the mechanics of materials provides a suitable and convenient means to determine the composites' elastic properties. Here, some basic assumptions are taken such that the composite is void-free, there is a perfect fiber-matrix bonding, size and shapes of the fibers are uniforms, the fibers are equally spaced, and the composite material exhibits linear and elastic behavior.

The stress $\sigma_{1}$ which acts on the uniform cross-sectional area 'A' of the representative volume element, $\sigma_{f}$ acts on fiber area $A_{f}$ and $\sigma_{m}$ acts on the uniform cross-sectional area $A_{m}$ of the matrix.

$$
\begin{aligned}
& P=\sigma_{2} A=\sigma_{f} A_{f}+\sigma_{m} A_{m} \\
& \sigma_{1}=E_{1} \varepsilon_{1} \\
& E_{1}=E_{f} \frac{A_{f}}{A}+E_{m} \frac{A_{m}}{A}
\end{aligned}
$$

Respective volume fractions for fiber and matrix are 
Thus,

$$
V_{f}=\frac{A_{f}}{A}, V_{m}=\frac{A_{m}}{A}
$$

$$
E_{1}=E_{f} V_{f}+E_{m} V_{m}
$$

where, $E_{m}$ and $E_{f}$ are Young's Elastic Modulus for the matrix and the fiber, respectively.

$$
E_{2}=\frac{E_{f} E_{m}}{V_{m} E_{f}+V_{f} E_{m}}
$$

The expression for a fraction of the load carried out by the fiber to that of the composite

$$
\frac{F_{f}}{F_{C}}=\frac{E_{f}}{E_{1}} \times v_{f}
$$

where, $\mathrm{F}_{f}$ and $\mathrm{F}_{C}$ are the uniaxial load shared by the fiber and the composite respectively. Now, the Major Poisson ratio

$$
v_{12}=-\frac{\varepsilon_{2}}{\varepsilon_{1}}
$$

The transverse deformation

$$
\begin{aligned}
& \boldsymbol{\Delta}_{\boldsymbol{w}}=-\boldsymbol{W}_{\varepsilon_{\mathbf{2}}}=\boldsymbol{W} \boldsymbol{v}_{\mathbf{1 2}} \boldsymbol{\varepsilon}_{\mathbf{1}} \\
& \boldsymbol{\Delta}_{\boldsymbol{w}}=\boldsymbol{\Delta}_{\mathrm{mw}}+\boldsymbol{\Delta}_{\mathrm{fw}} \\
& \boldsymbol{\Delta}_{\mathrm{mw}}=\mathrm{WV}_{\boldsymbol{m}} \boldsymbol{v}_{\boldsymbol{m}} \boldsymbol{\varepsilon}_{\mathbf{1}}, \boldsymbol{\Delta}_{\mathrm{fw}}=\mathrm{WV}_{\boldsymbol{f}} \boldsymbol{v}_{\boldsymbol{f}} \boldsymbol{\varepsilon}_{\mathbf{1}}, \boldsymbol{\Delta}_{\mathrm{fw}}=\mathrm{WV}_{\boldsymbol{f}} \boldsymbol{v}_{\boldsymbol{f}} \boldsymbol{\varepsilon}_{\mathbf{1}} \\
& \boldsymbol{v}_{\mathbf{1 2}}=\boldsymbol{v}_{\boldsymbol{m}} \boldsymbol{V}_{\boldsymbol{m}}+\boldsymbol{v}_{\boldsymbol{f}} \boldsymbol{V}_{\boldsymbol{f}}
\end{aligned}
$$

where, $v_{m}$ and $v_{f}$ are the Poisson's Ratio of the matrix and the fiber respectively. Also, the Minor Poisson ratio is,

$$
v_{21}=\frac{E_{2}}{E_{1}} \times v_{12}
$$

Also, $G_{f}=\frac{E_{f}}{2\left(1+v_{f}\right)}$ and $G_{m}=\frac{E_{m}}{2\left(1+v_{m}\right)}$

Finally,

$$
G_{12}=\frac{G_{m} G_{f}}{V_{m} G_{f}+\mathrm{V}_{f} G_{m}}
$$

where, $G_{f}$ and $G_{m}=$ Shear modulus of the fiber and matrix. Now, Longitudinal Tensile Strength is,

$$
\begin{aligned}
& \left(\varepsilon_{f}\right)_{u l t}=\frac{\left(\sigma_{f}\right)_{u l t}}{E_{f}} \\
& \left(\varepsilon_{m}\right)_{u l t}=\frac{\left(\sigma_{m}\right)_{u l t}}{E_{m}} \\
& \left(\sigma_{1}^{T}\right)_{u l t}=\left(\sigma_{f}\right)_{u l t} V_{f}+\left(\varepsilon_{f}\right)_{u l t} E_{m}\left(1-V_{f}\right)
\end{aligned}
$$

where, $\left(\sigma_{f}\right)_{u l t}$ and $\left(\sigma_{m}\right)_{u l t}$ are the ultimate tensile strengths of the fiber and matrix, and $\left(\varepsilon_{f}\right)_{u l t}$ and $\left(\varepsilon_{m}\right)_{u l t}$ are the ultimate failure strain of the fiber and matrix.

As stated earlier that assumptions are made in the model that there is a perfect fibermatrix bonding and fibers are spaced uniformly.

$$
\begin{aligned}
& \qquad\left(\varepsilon_{2}^{T}\right)_{u l t}=\left[\frac{d}{s}\left[\frac{E_{m}}{E_{f}}-1\right]+1\right] \\
& \left(\sigma_{2}^{T}\right)_{u l t}=E_{2} \times\left(\varepsilon_{2}^{T}\right)_{u l t}
\end{aligned}
$$


where, $\left(\varepsilon_{2}^{T}\right)_{u l t}$ is the ultimate transverse tensile strain of the lamina, and $\frac{d}{s}$ is the proportionate ratio of the diameter to the spacing ratio of the fiber (taken as 0.9994)

$$
\begin{array}{r}
\left(\gamma_{12}\right)_{m u l t}=\frac{\left(\tau_{12}\right)_{m u l t}}{G_{m}} \\
\left(\tau_{12}\right)_{u l t}=G_{12}\left[\frac{d}{s} \times \frac{G_{m}}{G_{f}}+\left(1-\frac{d}{s}\right)\right]\left(\gamma_{12}\right)_{u l t}
\end{array}
$$

where, $\left(\gamma_{12}\right)_{\text {mult }}$ is the ultimate shearing strain of the matrix, and

$\left(\tau_{12}\right)_{\text {mult }}$ is the ultimate shear strength of the matrix.

The finite element analysis (FEA) approach is used to evaluate the fundamental natural frequency of the EMC's and AMC's based composite plate for constant volume fraction (0.8). In this study, all sides fixed support boundary conditions, the dimensions of the plate taken as $0.5 \mathrm{~m}$ square plate with $0.0076 \mathrm{~m}$ thick.

\section{Results and Discussions}

The objectives of the work include the analytical solution of a composite rectangular plate and evaluating the strength of the composite plate with varying values of the parameters. From the solutions obtained and knowing the strength characteristics of the plate, it can be applied for various applications. To complete the objective of the work, an analytical solution for the problem has been developed using MATLAB. For this work, a plate volume size is taken as $1.9 \times 10^{-3} \mathrm{~m}^{3}$.

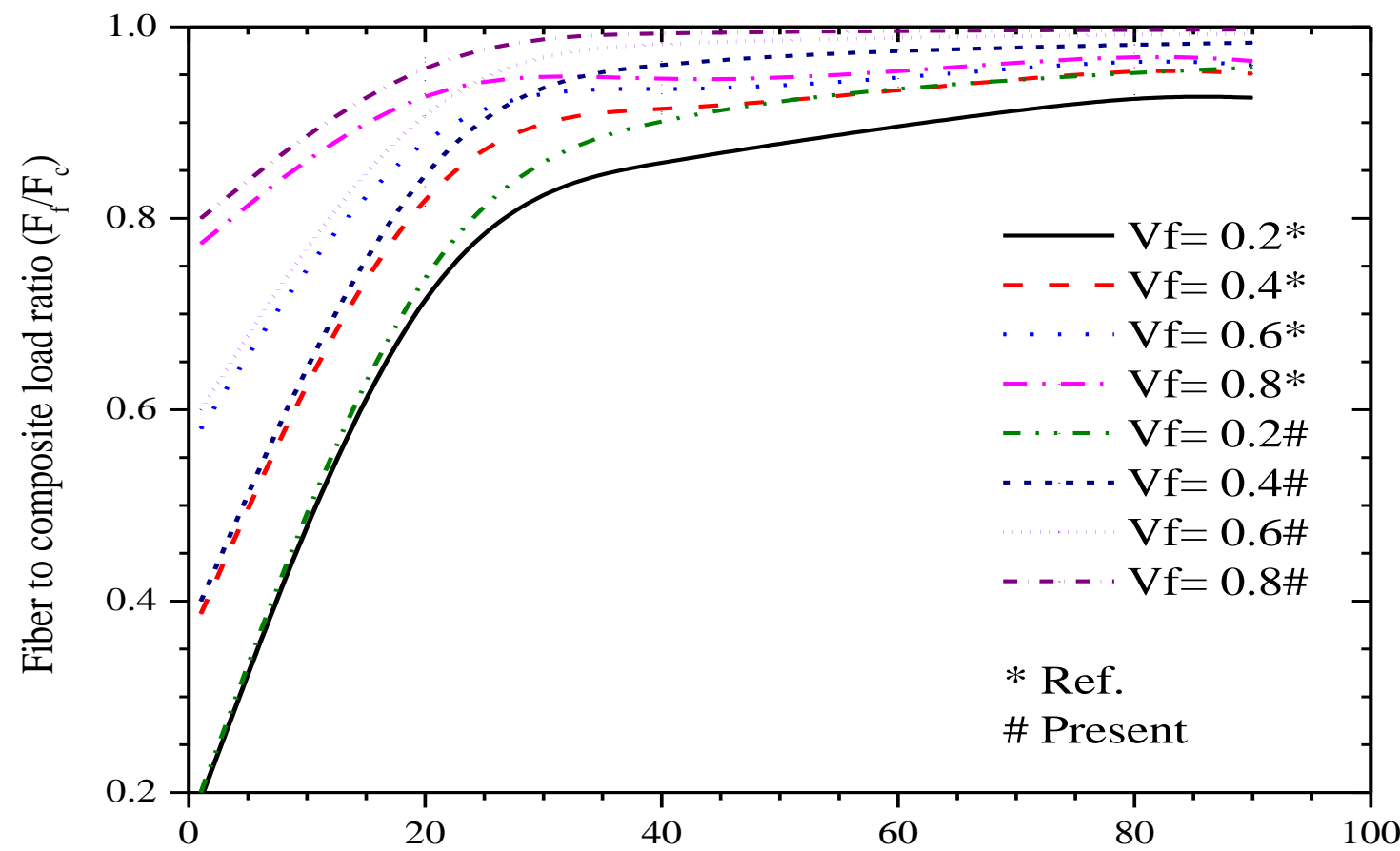

Fiber to Matrix Moduli Ratio, $\left(\mathrm{E}_{\mathrm{f}} / \mathrm{E}_{\mathrm{m}}\right)$

Figure 3. Theoretical $(*)$ value of the load carried by fibers of the composites as a function of the fraction of fiber-volume for a fixed ratio of fiber to matrix moduli $(\mathrm{G} / \mathrm{E})$ and their comparison with the present (\#) calculated values. 




(a)

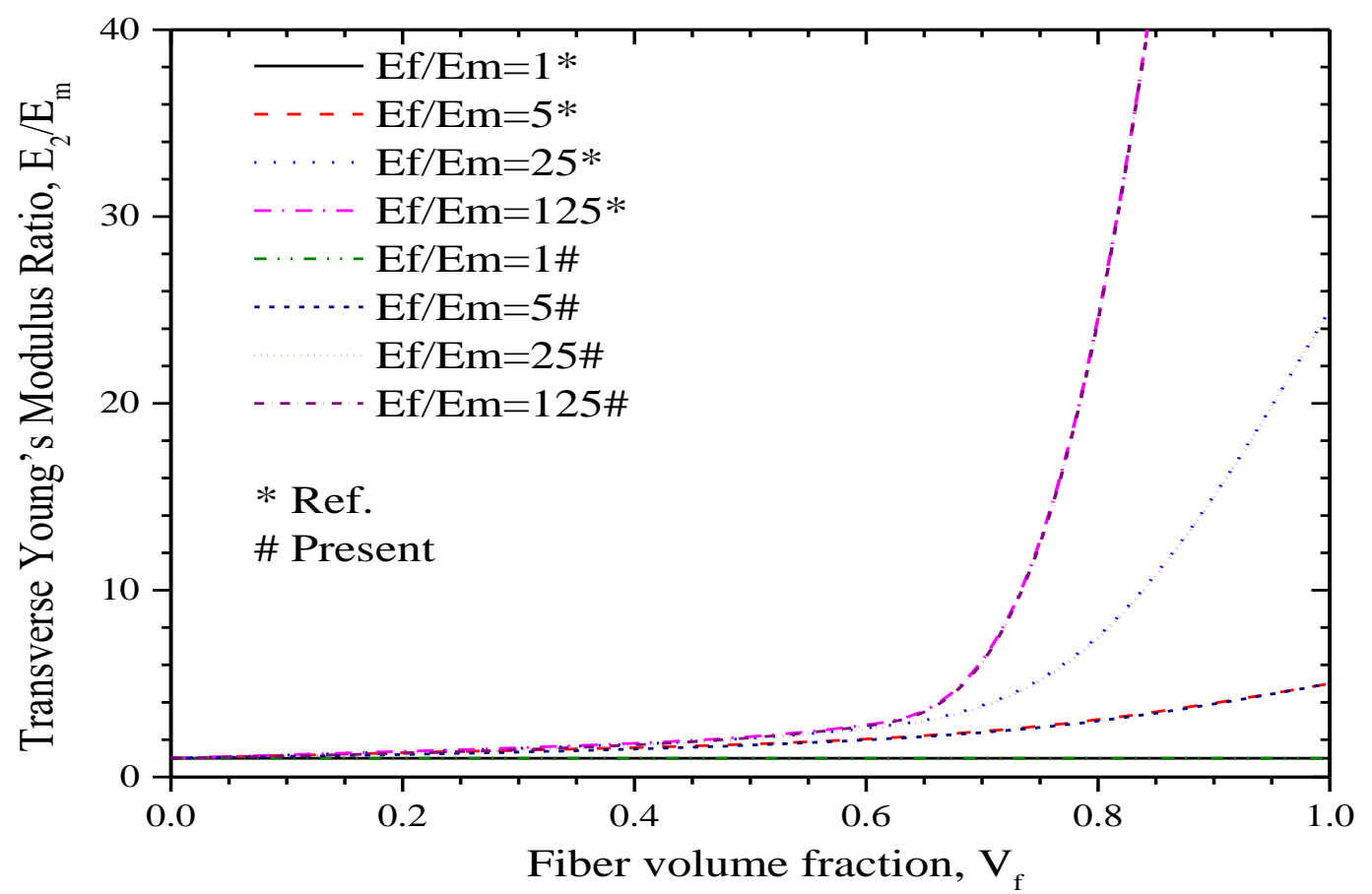

(b)

Figure 4. Theoretical (*) value of the (a) longitudinal; (b) transverse Young's Elastic Modulus as a function of the fraction of fiber-volume for a fixed ratio of fiber to matrix moduli $(\mathrm{G} / \mathrm{E})$ and their comparison with the present (\#) calculated values

Now, to validate the accuracy and credibility of the method presented here, the composite materials of the plate are selected as per the materials available in the literature. The evaluated numerical results were then compared with the results obtained from the present work for different cases and the literature Ref. [2], which are shown in Figures 3 and 4. 




(a)



(b)

Figure 5. Graphical representation of the (a) longitudinal; (b) transverse tensile strength to the matrix modulus ratio as a function of the fraction of fiber-volume for different materials of $\mathrm{G} / \mathrm{E}, \mathrm{Gr} / \mathrm{E}, \mathrm{A} / \mathrm{E}, \mathrm{C} / \mathrm{E}$, and MWCNT/E.

For G/E, Gr/E, A/E, C/E, and MWCNT/E materials, longitudinal and transverse tensile strength variation to the matrix modulus ratio was evaluated as a proportionate function fraction of fiber-volume, and it is shown in Figure 5. A similar analysis is exhibited in Figure 6. The variation of the in-plane shear strength to the matrix modulus ratio for the same materials is shown as a function of the proportionate fiber-volume fraction. 


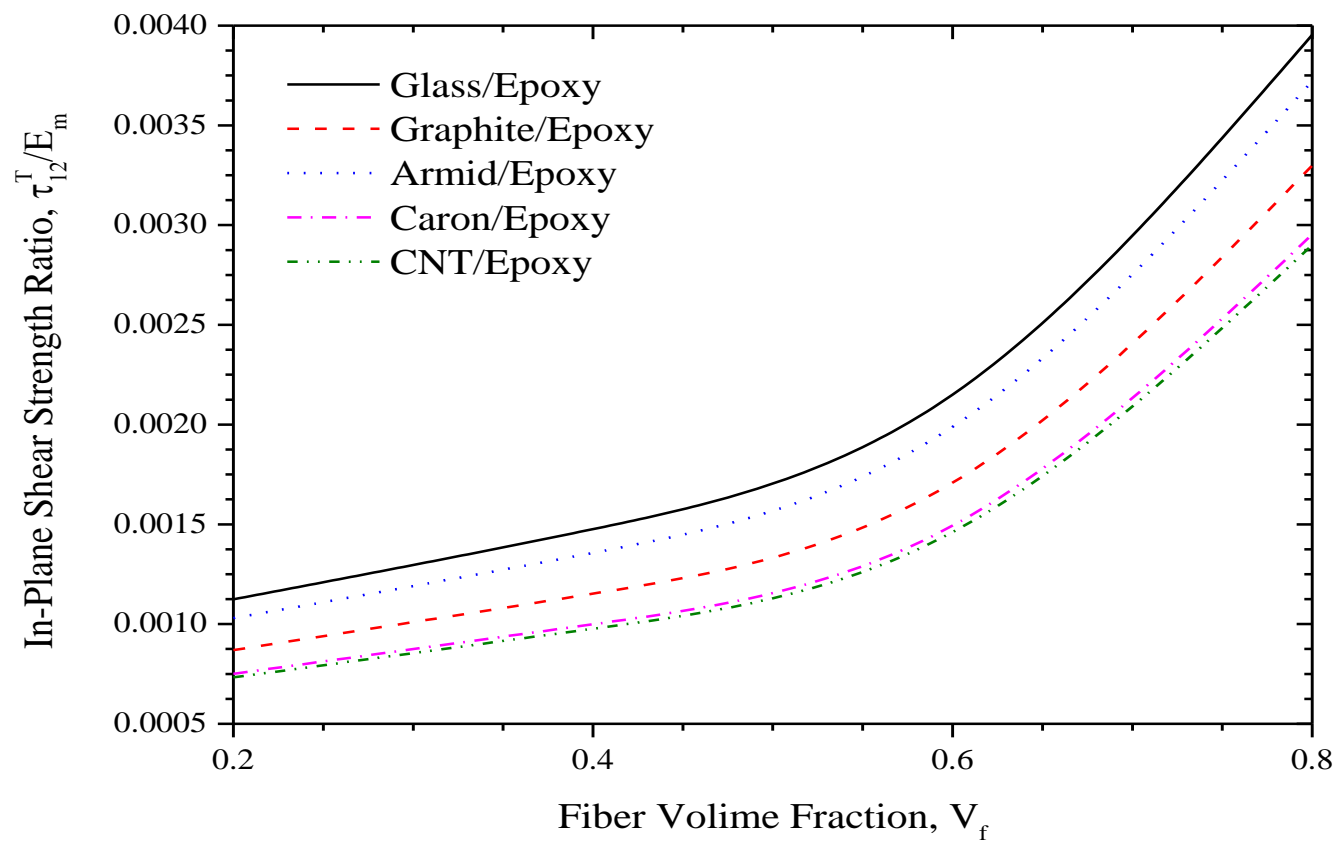

Figure 6. Graphical representation of the in-plane shear strength to the matrix modulus ratio as a function of the fraction of fiber-volume for different materials of G/E, Gr/E, A/E, C/E, and MWCNT/E

Further analysis has been carried out to analyze the longitudinal and transverse tensile strengths of the two composites comprising MWCNT/E (CNT/Epoxy) and CNT/A16061 (CNT/AL) matrix. Figure 7 exhibits the longitudinal and transverse tensile strength variation to the matrix modulus ratio as a function of the fraction of fiber-volume for the materials of MWCNT/E and MWCNT/A16061 matrix composites.



(a) 




(b)

Figure 7. Graphical representation of the (a) longitudinal; (b) transverse tensile strength to the matrix modulus ratio as a function of the fraction of fiber-volume for the materials of MWCNT/E and MWCNT/Al6061 matrix composite.

Similarly, Figure 8 shows the variation of the behavior of the in-plane shear strength to the matrix modulus ratio as a function of the proportionate fraction of the fiber-volume of the two composite materials comprising MWCNT/E and MWCNT/Al6061 matrix. Next, fundamental natural frequencies are evaluated and analyzed to study the behavior against mechanical vibration using finite element analysis technique and MATLAB for which contour plots are obtained for different composite materials.



Figure 8. Graphical representation of the in-plane shear strength to the matrix modulus ratio as a function of fiber volume fraction of MWCNT/E and MWCNT/A16061 matrix composite 
The fiber-to-matrix moduli ratio in polymeric composites is extremely high. In such instances, only substantial fiber volume fractions influence the composite's longitudinal, transverse Young's, and in-plane shear modulus. The contribution of the fiber modulus only becomes significant when the fiber volume percentage exceeds $80 \%$ in these figures. Due to the geometry of fiber packing, certain fiber volume fractions are not practicable and, in many situations, physically impossible.

Figure 9 and Figure 10 show the contour plots of fundamental natural frequency and deformation behavior of composite plate with different fiber considerations like; G/E, Gr/E, $\mathrm{A} / \mathrm{E}, \mathrm{C} / \mathrm{E}, \mathrm{MWCNT} / \mathrm{E}$, and MWCNT/A16061. For all six materials, all the sides of the composite plates have fixed boundary conditions.

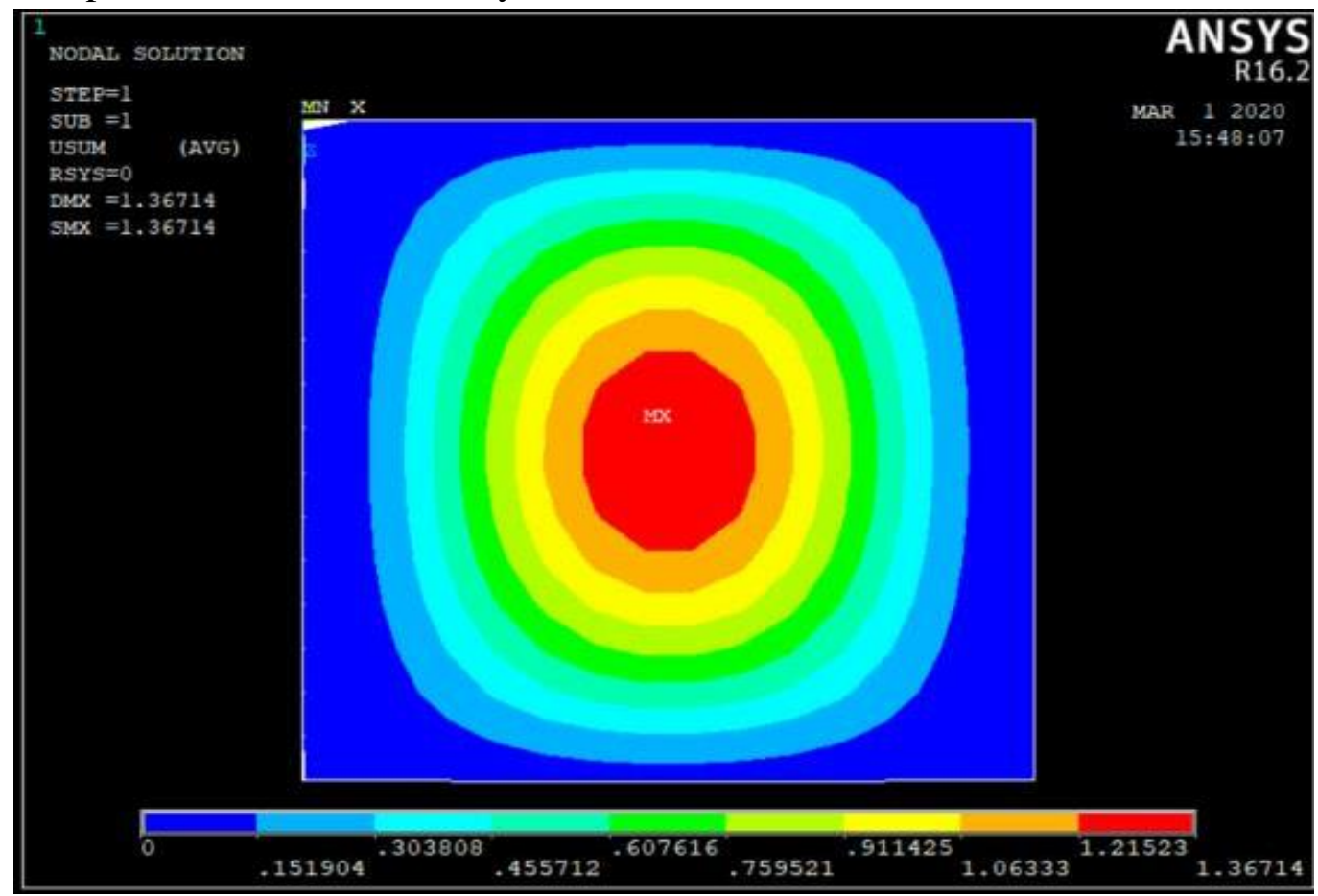

(a)

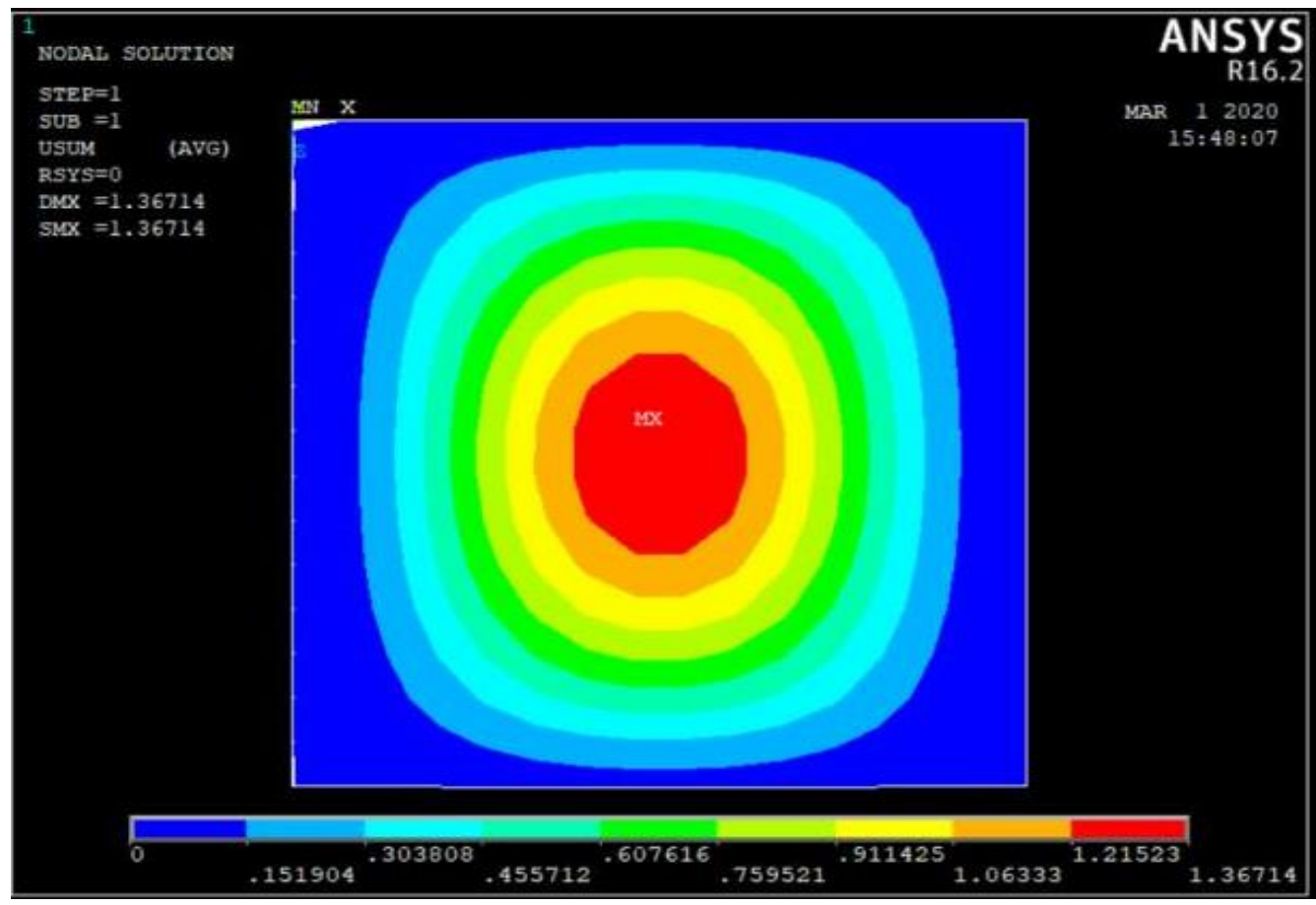

(b) 


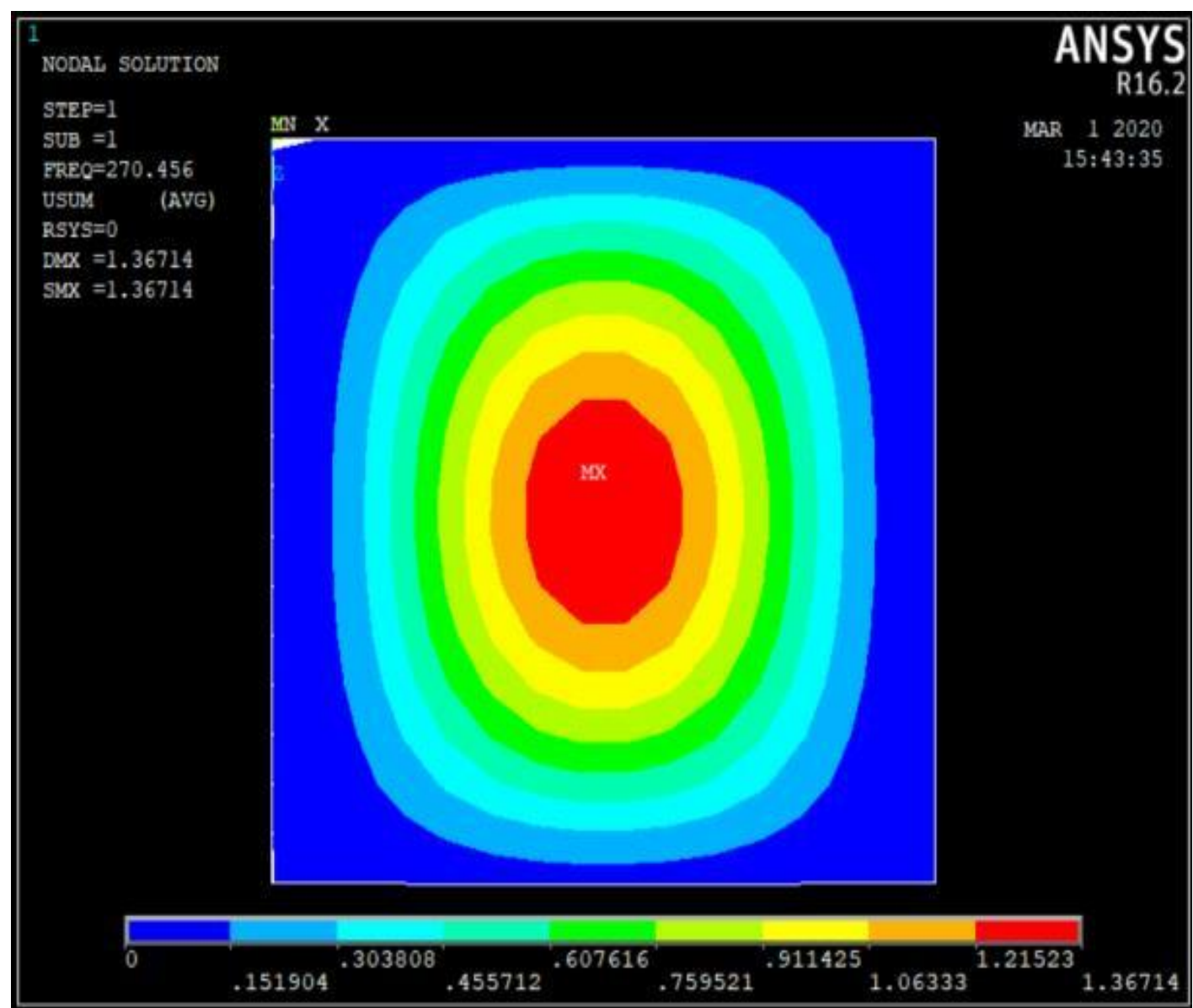

(c)



(d) 


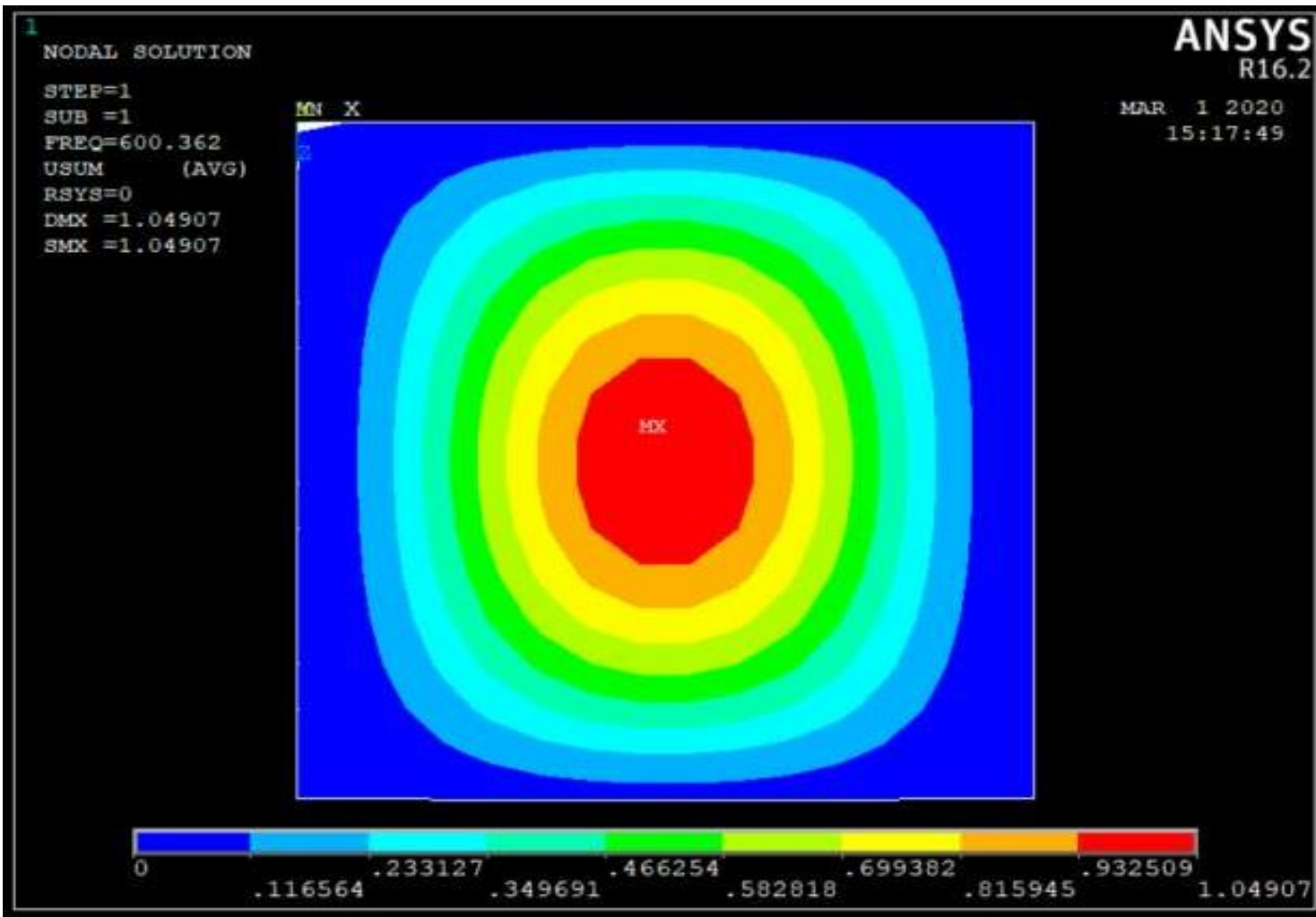

(e)



(f)

Figure 9. Fundamental natural frequency of (a) G/E; (b) Gr/E; (c) A/E; (d) C/E; (e) MWCNT/E; (f) MWCNT/Al6061 matrix composite plate with all side fixed boundary condition. 


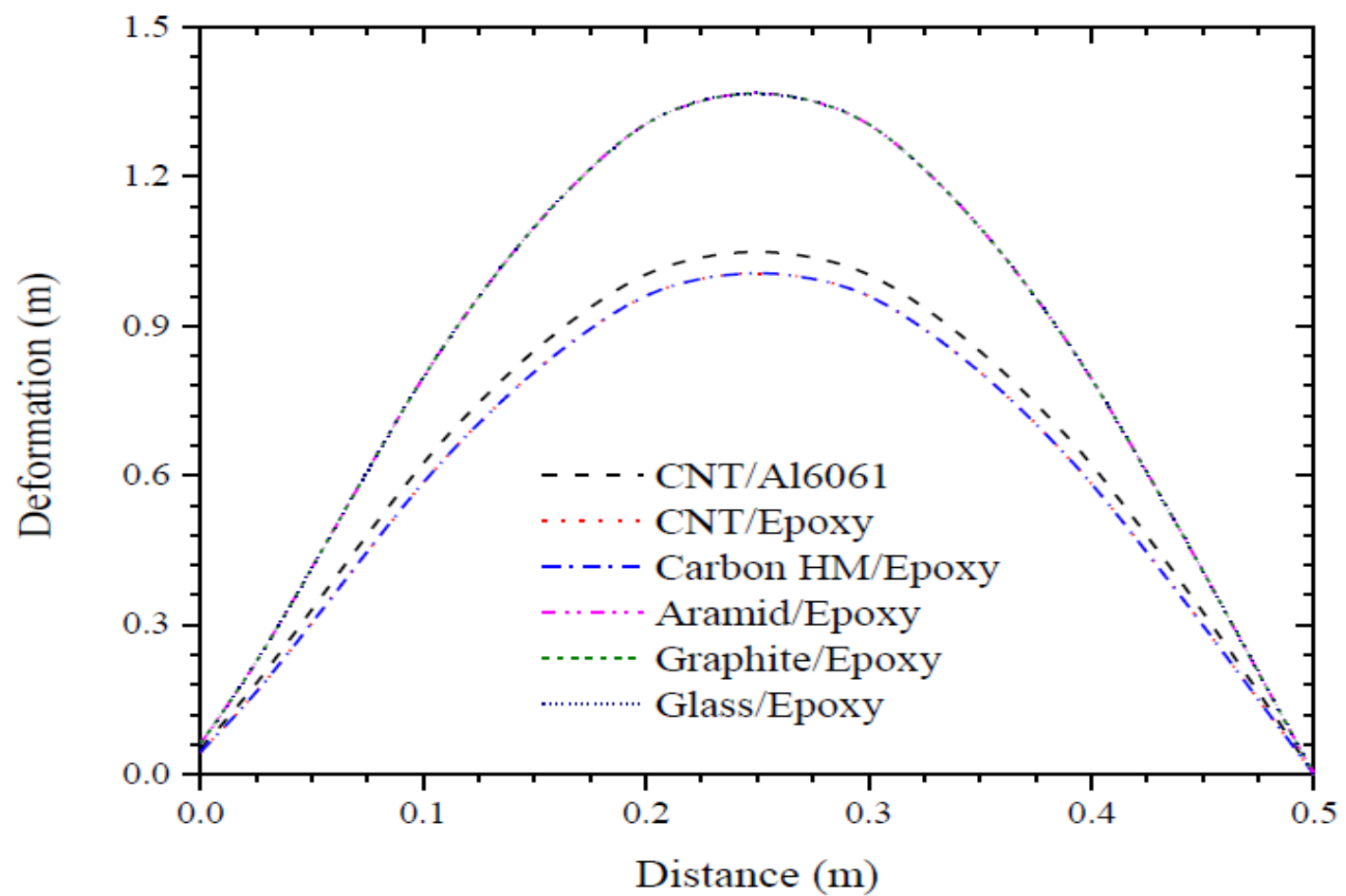

Figure 10. Variation of deformation behavior of the composite plate for different fibers with all side fixed boundary conditions.

From Figure 9 and Figure 10, it has been clearly observed that the maximum deflection occurs in the mid of the plate for all the six composite structures taken. It is also observed that the minimum value of all the maximum deformations is obtained in the composite plates of C/E, MWCNT/E, and MWCNT/Al6061.

\section{Conclusions}

The major conclusions from the analytical solution are drawn, which are as follows: Different fiber/epoxy composite material has been investigated, and ultimate strength of composite plate is evaluated. The numerical solution shows that the increased volume fraction of fiber increases the ultimate tensile strength (longitudinal and transverse) and in-plane shear strength. And it is high for MWCNT/E composite material; Effect of variation in Young's modulus ratio of composite plates on their respective ultimate strengths have been performed, and it is found that the strength of composite plate decreases if E1/E2 = 1 to 25, and after that, it remains almost the same for all. And the maximum ultimate strength has been found for MWCNT/E composite and minimum of Aramid/Epoxy composite; In addition, the ultimate strength of MWCNT/E as well as MWCNT/Aluminum- composite has been investigated. In the present work, $\mathrm{Al} 6061$ matrix has been used due to its higher strength. It has been seen that the aluminum-based CNT gives more strength as compared to epoxy-based composite; Previous literature shows that the yield strength of 6061-aluminum is significantly higher than 6063- aluminum; for this reason, 6061-aluminum is usually preferred over 6063-aluminum; The present study reveals out that for a given boundary condition, the deformation value is minimum for C/E and MWCNT/E and MWCNT/A16061. It is also concluded that the behavior of the fundamental natural frequency is minimum for Glass/Epoxy and maximum for MWCNT/A16063 composite plate; The novelty of the work is to investigate the different fiber as well as polymer and metal matrix composite. According to different available kinds of literature, the 6063-aluminum alloy is mostly used in the metal matrix. But in the present work, 
the 6061-aluminum alloy has been used, and it has been found that it gives reasonably better results.

\section{Funding}

This research was funded by Technical Education Quality Improvement Programme (TEQIP III) by Chhattisgarh Swami Vivekanand Technical University, Bhilai, Project Grant No. CSVTU/CRP/TEQIP-III/32.

\section{Acknowledgments}

The authors are heartily thankful to Shri Shankaracharya Technical Campus, Shri Shankaracharya Group of Institutions, Bhilai, for providing infrastructural support for carrying out the present research work.

\section{Conflicts of Interest}

The authors declare no conflict of interest.

\section{References}

1. D. D. L. Chung, "Book Chapter 4 - Properties of Carbon Fibers," in Carbon Fiber Composites, D. D. L. Chung, Ed. Boston: Butterworth-Heinemann, 65-78, 1994.

2. Sampath, P.; Santhanam, S.K.V. Effect of moringa and bagasse ash filler particles on basalt/epoxy composites. Polímeros 2019, 29, https://doi.org/10.1590/0104-1428.01219.

3. Bulut, M.; Bozkurt, Ö.Y.; Erkliğ, A.; Yaykaşlı, H.; Özbek, Ö. Mechanical and Dynamic Properties of Basalt Fiber-Reinforced Composites with Nanoclay Particles. Arab. J. Sci. Eng. 2020, 45, 1017-1033, https://doi.org/10.1007/s13369-019-04226-6.

4. Ulus, H.; Kaybal, H.B.; Eskizeybek, V.; Avc1, A. Enhanced Salty Water Durability of Halloysite Nanotube Reinforced Epoxy/Basalt Fiber Hybrid Composites. Fibers Polym. 2019, 20, 2184-2199, https://doi.org/10.1007/s12221-019-9316-y.

5. Toorchi, D.; Khosravi, H.; Tohidlou, E. Synergistic effect of nano-ZrO2/graphene oxide hybrid system on the high-velocity impact behavior and interlaminar shear strength of basalt fiber/epoxy composite. J. Ind. Text. 2019, https://doi.org/10.1177/1528083719879922.

6. Kumar, C.V.; Kandasubramanian, B. Advances in Ablative Composites of Carbon Based Materials: A Review. Ind. Eng. Chem. Res. 2019, 58, 22663-22701, https://doi.org/10.1021/acs.iecr.9b04625.

7. Naidu, P.P.; Raghavendra, G.; Ojha, S.; Paplal, B. Effect of g-C $3 \mathrm{~N} 4$ nanofiller as filler on mechanical properties of multidirectional glass fiber epoxy hybrid composites. J. Appl. Polym. Sci. 2020, 137, https://doi.org/10.1002/app.48413.

8. Parveen, S.; Pichandi, S.; Goswami, P.; Rana, S. Novel glass fibre reinforced hierarchical composites with improved interfacial, mechanical and dynamic mechanical properties developed using cellulose microcrystals. Mater. Des. 2020, 188, https://doi.org/10.1016/j.matdes.2019.108448.

9. Bagci, M.; Demirci, M.; Sukur, E.F.; Kaybal, H.B. The effect of nanoclay particles on the incubation period in solid particle erosion of glass fibre/epoxy nanocomposites. Wear 2020, 444, https://doi.org/10.1016/j.wear.2019.203159.

10. Domun, N.; Kaboglu, C.; Paton, K.R.; Dear, J.P.; Liu, J.; Blackman, B.R.K.; Liaghat, G.; Hadavinia, H. Ballistic impact behaviour of glass fibre reinforced polymer composite with 1D/2D nanomodified epoxy matrices. Compos. Part B Eng. 2019, 167, 497-506, https://doi.org/10.1016/j.compositesb.2019.03.024.

11. Burda, I.; Barbezat, M.; Brunner, A.J. Delamination resistance of GFRP-epoxy rods with nanoparticle- and microparticle-modified matrix and its correlation with the fracture properties of epoxy nanocomposites. Fatigue Fract. Eng. Mater. Struct. 2020, 43, 292-307, https://doi.org/10.1111/ffe.13122.

12. Behera, M., Biswal, S. K., Ahemad, M. A., \& Panda, B.S. Demonstration of Enhanced Thermal Stability, Dielectric Constant and Low Tangent Loss by Particle-Reinforced Silver/poly (Vinylidene Difluoride) 
Polymer Nanocomposites. Biointerface Research in Applied Chemistry. 2021, 11, 12584-12595, https://doi.org/10.33263/BRIAC115.1258412595.

13. Sirajudheen, P.; Nikitha, M.R.; Karthikeyan, P.; Meenakshi, S. Perceptive removal of toxic azo dyes from water using magnetic $\mathrm{Fe} 3 \mathrm{O} 4$ reinforced graphene oxide-carboxymethyl cellulose recyclable composite: Adsorption investigation of parametric studies and their mechanisms. Surfaces and Interfaces. 2020, 21, 100648, https://doi.org/10.1016/j.surfin.2020.100648.

14. Iervolino, G.; Vaiano, V.; Palma, V. Enhanced azo dye removal in aqueous solution by $\mathrm{H} 2 \mathrm{O} 2$ assisted nonthermal plasma technology. Environmental Technology \& Innovation. 2020, 19, 100969, https://doi.org/10.1016/j.eti.2020.100969.

15. Kang, H.; Kwon, S.H.; Lawler, R.; Lee, J.H.; Doo, G.; Kim, H.-T.; Yim, S.-D.; Jang, S.S.; Lee, S.G. Nanostructures of Nafion Film at Platinum/Carbon Surface in Catalyst Layer of PEMFC: Molecular Dynamics Simulation Approach. The Journal of Physical Chemistry C. 2020, 124, 21386-21395, https://doi.org/10.1021/acs.jpcc.0c03651.

16. Mais, L.; Vacca, A.; Mascia, M.; Usai, E.M.; Tronci, S.; Palmas, S. Experimental study on the optimisation of azo-dyes removal by photo-electrochemical oxidation with $\mathrm{TiO} 2$ nanotubes. Chemosphere. 2020, 248, 125938, https://doi.org/10.1016/j.chemosphere.2020.125938.

17. Sirajudheen, P.; Karthikeyan, P.; Basheer, M.C.; Meenakshi, S. Adsorptive removal of anionic azo dyes from effluent water using $\mathrm{Zr}(\mathrm{IV})$ encapsulated carboxymethyl cellulose-montmorillonite composite. Environmental Chemistry and Ecotoxicology. 2020, 2, 73-82, https://doi.org/10.1016/j.enceco.2020.04.002.

18. Chaudhary, V.; Bajpai, P.K.; Maheshwari, S. Effect of moisture absorption on the mechanical performance of natural fiber reinforced woven hybrid bio-composites. J. Nat. Fibers 2020, 17, 84-100, https://doi.org/10.1080/15440478.2018.1469451.

19. Moradnia, F.; Taghavi Fardood, S.; Ramazani, A.; Gupta, V.K. Green synthesis of recyclable MgFeCrO4 spinel nanoparticles for rapid photodegradation of direct black 122 dye. Journal of Photochemistry and Photobiology A: Chemistry 2020, 392, https://doi.org/10.1016/j.jphotochem.2020.112433.

20. Dereli, G.; Süngü, B. Temperature dependence of the tensile properties of single-walled carbon nanotubes: O (N) tight-binding molecular-dynamics simulations. Physical Review B 2007, 75, 184104, https://doi.org/10.1103/PhysRevB.75.184104.

21. Esawi, A.M.K.; Morsi, K.; Sayed, A.; Taher, M.; Lanka, S.J.C.S. Effect of carbon nanotube (CNT) content on the mechanical properties of CNT-reinforced aluminium composites. Composites Science and Technology 2010, 70, 2237-2241, https://doi.org/10.1016/j.compscitech.2010.05.004.

22 Kim, H.H.; Babu, J.S.S.; Kang, C.G. Fabrication of A356 aluminum alloy matrix composite with CNTs/Al2O3 hybrid reinforcements. Materials Science and Engineering: A 2020, 573, 92-99, https://doi.org/10.1016/j.msea.2013.02.041.

23. Basariya, M.R.; Srivastava, V.C.; Mukhopadhyay, N.K. Microstructural characteristics and mechanical properties of carbon nanotube reinforced aluminum alloy composites produced by ball milling. Materials \& Design 2014, 64, 542-549, https://doi.org/10.1016/j.matdes.2014.08.019.

24. Dey, S.; Mukhopadhyay, T.; Spickenheuer, A.; Gohs, U.; Adhikari, S., 2016. Uncertainty quantification in natural frequency of composite plates-An Artificial neural network based approach. Advanced Composites Letters 2016, 25, 43-48, https://doi.org/10.1177/096369351602500203.

25. Farrash, S.M.H.; Shariati, M.; Rezaeepazhand, J. The effect of carbon nanotube dispersion on the dynamic characteristics of unidirectional hybrid composites: An experimental approach. Composites Part B: Engineering 2017, 122, 1-8, https://doi.org/10.1016/j.compositesb.2017.04.003.

26. Reddy, R.M.R.; Karunasena, W.; Lokuge, W. Free vibration of functionally graded-GPL reinforced composite plates with different boundary conditions. Aerospace Science and Technology 2018, 78, 147-156, https://doi.org/10.1016/j.ast.2018.04.019.

27. Wang, A.; Chen, H.; Hao, Y.; Zhang, W. Vibration and bending behavior of functionally graded nanocomposite doubly-curved shallow shells reinforced by graphene nanoplatelets. Results in Physics $\mathbf{2 0 1 8 ,}$ 9, 550-559, https://doi.org/10.1016/j.rinp.2018.02.062.

28. Safaei, B.; Ahmed, N.A.; Fattahi, A.M. Free vibration analysis of polyethylene/CNT plates. The European Physical Journal Plus 2019, 134, 271, https://doi.org/10.1140/epjp/i2019-12650-x.

29. Wang, M.; Xu, Y.G.; Qiao, P.; Li, Z.M. A two-dimensional elasticity model for bending and free vibration analysis of laminated graphene-reinforced composite beams. Composite Structures 2019, 211, 364-375, https://doi.org/10.1016/j.compstruct.2018.12.033. 
30. Ayan, M.Ç.; Kiriş, S.; Yapici, A.; Karaaslan, M.; Akgöl, O.; Altıntaş, O.; Ünal, E. Investigation of cotton fabric composites as a natural radar-absorbing material. Aircraft Engineering and Aerospace Technology 2020, 92, 1275-1280, https://doi.org/10.1108/AEAT-01-2020-0018. 